\title{
USING AHP IN PRIORITIZATION OF THE PROCUREMENT PROPOSALS IN UNIVERSITIES
}

\author{
Nilgun MORALI \\ Aegean University \\ Department of Statistics \\ Faculty of Science \\ 35100 Bornova, Izmir. Turkey
}

\begin{abstract}
In the beginning of each budget planning period in universities, procurement proposals from all clepartment are collected, and a comparative evaluation is made befor allocation of resources. It is decision maker: responsibility to prioritize the proposals, eliminate some of them, and give place to the remaining ones in the budget with respect to their eligibility.

In this study, we present an evaluation model for obtaining the benefits of the procurement proposals using Analyik Hierarchy Process, which makes it possible to represent all relevant factors, opinions and interdependence of all influential and influenced groups. We then propose two algorithms on benefit/cost basis: one for selecting the proposals which will take part in the budget, and one for budget allocation.
\end{abstract}

\section{INTRODUCTION}

Supplying the needs of a university is a long and complex process which sometimes lasts more than a year. The process starts with specifying the needs, selecting the ones to be supplied within budget restrictions, then bidding, evaluating the alternatives, and ending with procurement. This process, in general, is a sequential decision making process where outputs of each stage produces the inputs of the subsequent stage. Each stage can also be handled as a distinct decision problem, where some of which can be combined in a single model.

Universities planning/budgeting problem combines the first two stages, and involves in determining the needs and necessary amounts of money in order to achieve the goels of the university in a single or multi-period basis. This problem. and approaches to modeling and solution are discussed by Arbel [1], Kwak and Diminnie [3], Sinuany-Stern [6]. Schroeder [5] One of the common points in these studies is that they consider the different objectives of unversities and represent them in one model. Besides, Kwak and Diminnie notes on the importance and necessity of embodiment of purposes of administrators, faculty, and students in hudgeting decisions, and describes this as a crucial issue in university administration.

In this study we approach the problem on a practical basis, and propose an evaluatun model and an allocation algorithm which intends to satisfy many diverse groups within the university. We base the reasoning on our experience in Turkish universities, where budget planning is made in two stages. The first stage is selection (or elimination) of the needs to be satisfied in that period. and the second stage is resource allocation with only one resource limited by budget.

Budget planning starts with collection of procurement proposals, which state the 
significance of the need and lower-upper bounds of necessary expenditure. from all the departments and administrative sections. In general demands for procurement are on diverse areas; e.g. renewing chairs and boards in the classrooms. upgrading the administrative network. providing books for the library, new experiment devices for the laboratory, service cars for top management. personal computers for faculty or computer lab. The final plan depends on the targets of the university, influential powers of the demanding departments. and their ability (or success) to convince others in the significance of their needs. as well as the cost figures and budget restrictions. Therefore, a formal approach which makes it possible to represent all relevant factors, opinions and interdependence of all influential and influenced groups in determining the benefits of procurement proposals becomes necessary.

In evaluating the benefits of procurement proposals. we use Analytic Hierarchy Process (AHP) developed by Saaty [4], and its microcomputer software application Expert Choice (EC) (of Forman et. al. [2]). which enable us structure the complexity by a hierarchy. In Section 2 . we present the structure of the hierarchy. and in Section 3, we give an illustrative example in Section 4. we propose two algorithms on benefit/cost basis; one for selecting the propusals which will take part in the budget. and one for budget allocation.

\section{PROCUREMENT PROPOSALS EVALUATION MODEL}

The goal of the model is to evaluate the procurement proposals and determine their benefits. independent from each other. which will constitute a basis for the allocation ol resources at the beginning of the budget planning period. The model is built on four levels of hierarchy as summarized in Table 1. and shown in detail in Figure 1. We built the hierarchy using top-down approach; starting with the objectives of the university in the first level. influential groups (actors) in the second level, and criteria in the third level. We use rating model, by which absolute evaluation of hundreds of proposals can be obtained independent from each other. Therefore fourth level of the hierarchy consists of intensities, and alternatives take place in the fifth level. The purpose is to obtain ratings representing the benefits of proposals which are to be used in resource allocation.

Table 1. Levels of Hierarchy in Procurement Proposals Evaluation Model

\begin{tabular}{|c|c|c|c|}
\hline 1 Level & 2. Level & 3 Level & 4 Level \\
\hline OBJECTIVES & ACTORS & CRITERIA & INTENSITIES \\
\hline $\begin{array}{l}\text { 1 } 1 . \text { Education } \\
1.2 \text { Research } \\
\text { 1.. Admunistrative } \\
\text { Services }\end{array}$ & $\begin{array}{l}\text { 2.1. Faculty Members } \\
2.2 . \text { Students } \\
2.3 \text { Technicians } \\
\text { 2.4.Potential Ciıents } \\
\text { 2.5.Administratıng } \\
\text { Personnel }\end{array}$ & $\begin{array}{l}\text { 3.1.Advancements in the } \\
\text { State of the Art } \\
\text { 3.2. Saving Time } \\
\text { 3.3.Improvement in } \\
\text { Quality of Knowledge } \\
\text { 3.4.Better Environment } \\
\text { 3.5.Profitability }\end{array}$ & $\begin{array}{l}\text { 4.1. High } \\
\text { 4.2.Average } \\
\text { 4.3.Low }\end{array}$ \\
\hline
\end{tabular}


Evaluatior of Procurement proposals

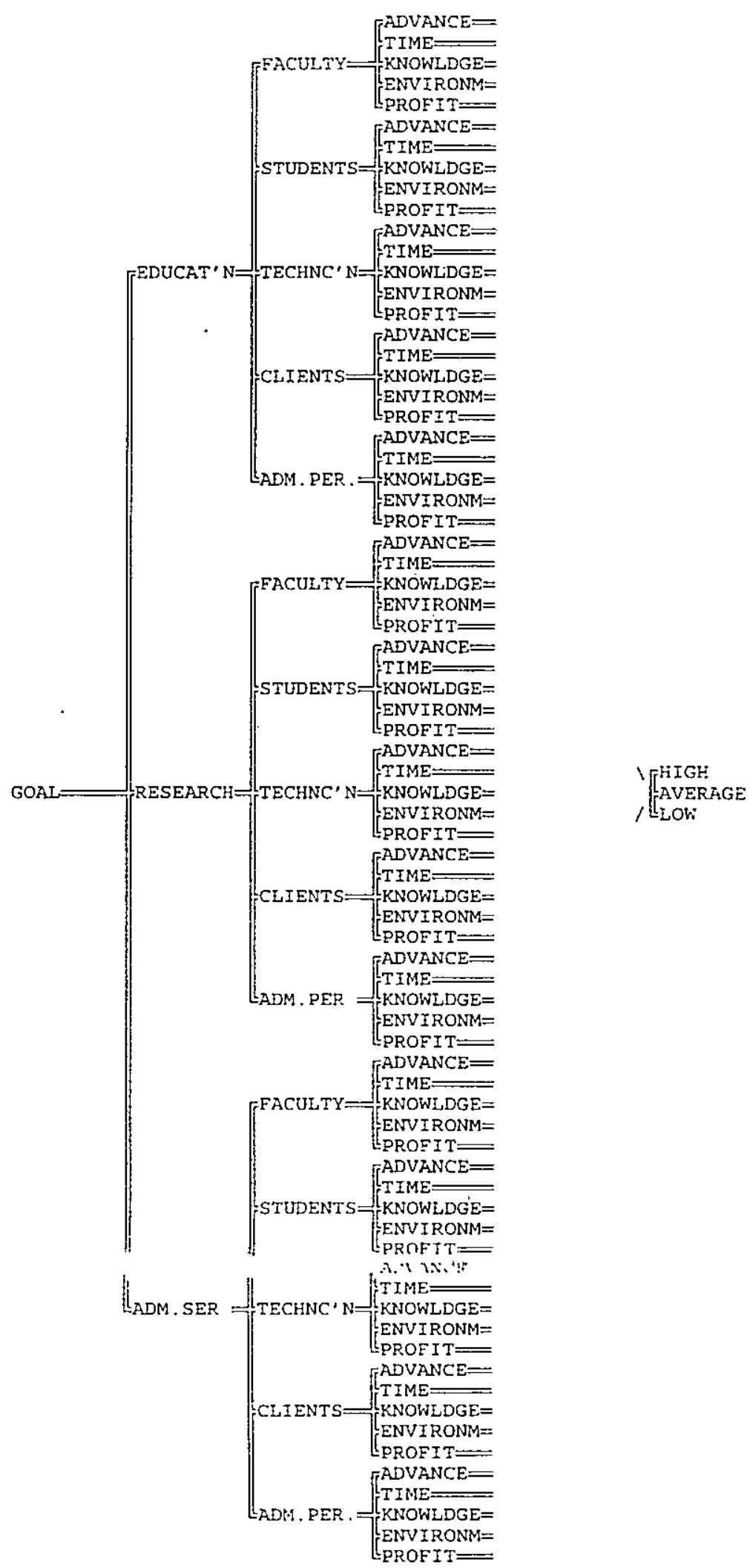

Figure 1. Value Tree for the Evaluation of Procurement Proposals 


\subsection{Objectives}

Since the universities can be considered as service producing firms in economical torms. their goal is to improve the quality of the service with minimum cost: or in other words. 1 get maximum benefit with limited resources. Three major services are carried out in a unversit! (1) education. (2) research. and (3) administrative services. improvements in which are the objectives of the university. In Figure 2, we present these objectives (EI)( C $\left.A l^{\prime} .{ }^{\prime}\right)$. (RESEARCH). (ADM SER) respectively in the first level of the hierarchy. Priorities of these objectives depend on the global policy of the university, which in fact changes by time.

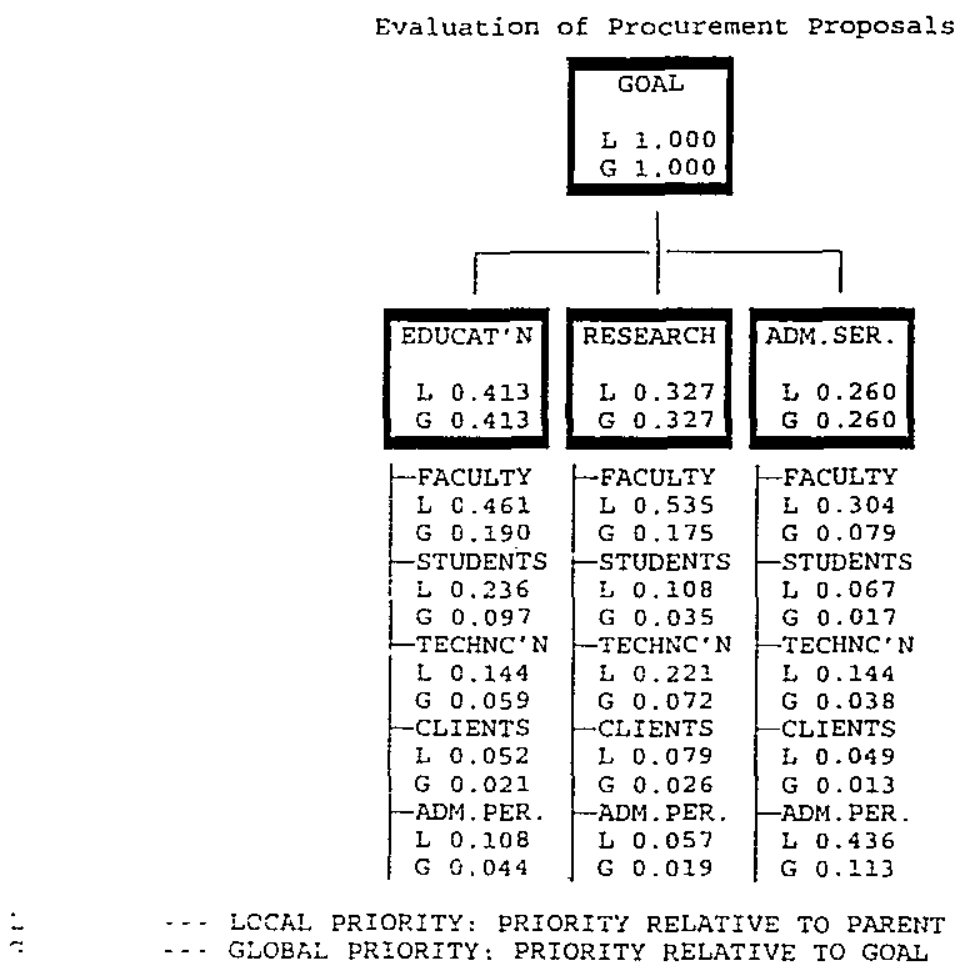

Figure 2. Objectives and Actors in Evaluating Procurement Proposals

\subsection{Actors}

The second level of the model involves the actors. These are the groups of people who are influenced by the investments and expenditures of the university, and also have influtential power on the decisions. Their tasks and benefits are interrelated to each other. but the have different preferences. In Figure 2. we present the actors in five groups, which are

11) Faculty members (FACULTY), who take major responsibility in education and research activities:

(2) Students (STUDENTS), who take benefit of works of all other groups by means of education:

(3) Technicians (TECHNC'N), who are the support personnel in all services of the unversit! 
in using and maintaining the technical devices, in a way carrying out the most tedious part of lahoratory works for all services:

(4) Potential clients (CLIENTS), who get service from the universities and take adventage of the public services of university`s educational and research affairs as a by-product: e.g. patients in the university hospitals, firms getting consultance from engineering schools. etc:

(5) Administrative personnel (ADM.PER.), who are responsible for all official work and operations in the university.

Their interests and interdependence with the objectives of the university differ from each other. Therefore, their evaluations would have different influence (weight) with respect to each objective, as shown in Figure 2. For example, administrative personnel will have more influence on the decisions related with administrative services, compared to their influence on research expenditures.

\subsection{Criteria}

There are five main criteria which has different priorities for each actor as shown in Figure 3: rooted from education objective where the same scheme applies for the other objectives. These are:

(1) Advancements in the state of the art (ADVANCE), which enables the actors to reflect their concern in the improvements in technology:

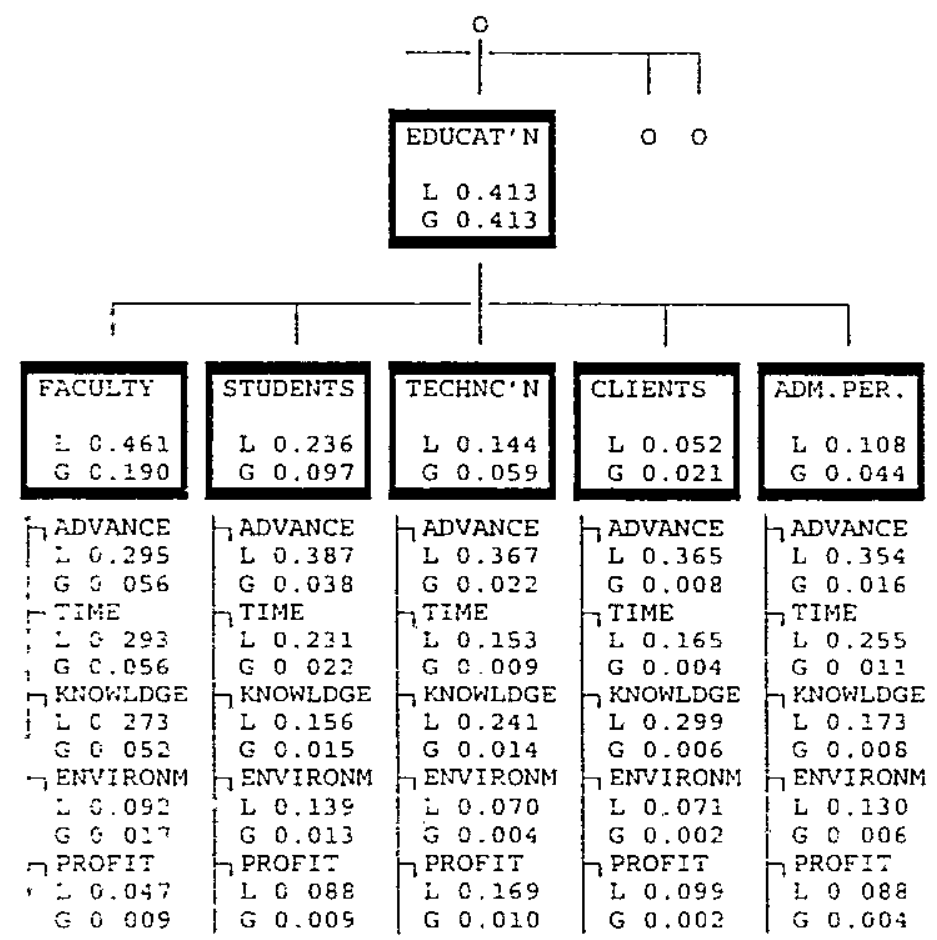

Figure 3. Actors and Criteria in Evaluating Procurement Proposals 
(2) Saving time (TIME), which also means speeding up the operations or services:

(3) Improving quality of knowledge (KNOWLDGE), which may also be interpreted as reinatilu! or certainty of results which will be provided;

(4) Better environment (ENVIRONM), is improving security conditions, as well as getting more comfortable. and more enjoyable environment;

(5) Profitability (PROFIT), which means gaining money on the side of the actors who make therr lives in the university (namely; faculty members, technichians, and administrative personnel). and saving money on the side of the actors who pay for the services of the university who are students and potential clients.

\subsection{Rating Intensities}

The forth level of the hierarchy consists of three levels of rating intensities (1) high. (2) average, and (3) low for all criteria, importance of which depend on criteria. actor. objective chain. In Figure 4, we present these rooting from faculty under education.

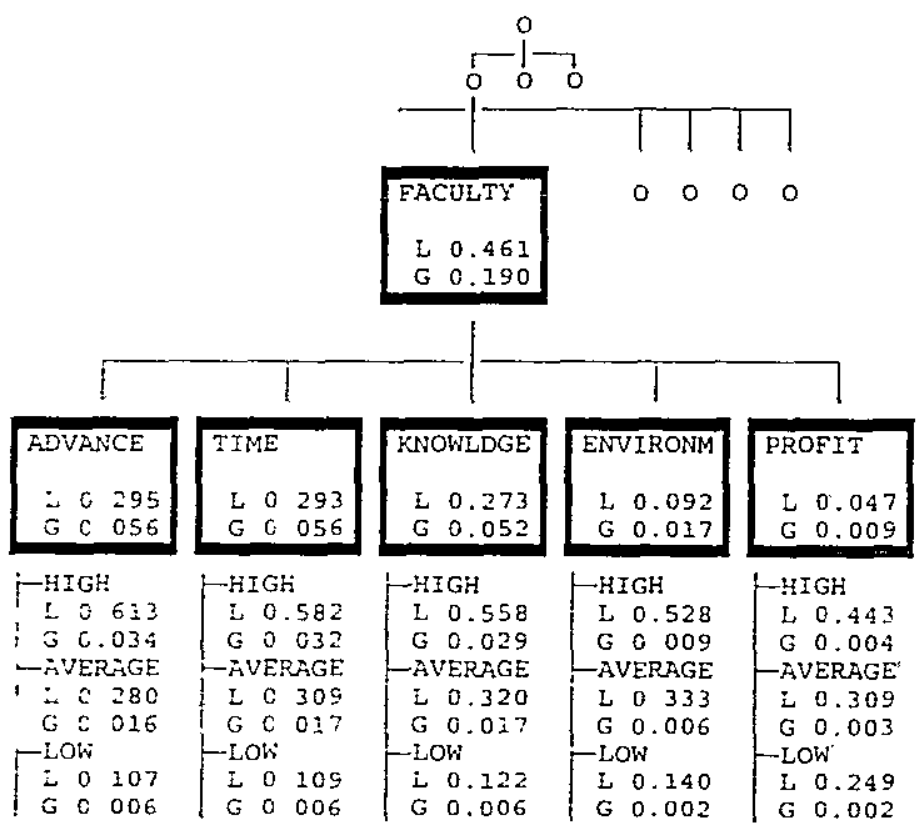

Figure 4. Rating Intensities in Evaluating Procurement Proposals

\subsection{Alternatives}

Alternatives are the procurement proposals which may be on diverse areas from a shutte bus to a computer. or a telephone network, or a hightech device to be used in research laboraties. Our hierarchy suggests to rate each procurement proposal for all criterlat by each actors with respect to each one of the objectives of the university. 


\section{AN ILLUSTRATIVE EXAMPLE}

Since this study is not intended to present the results of an applied study, we restrict our concern only on faculty members' point of view, without loss of generality in the following example. We present the value tree with only one actor (FACULTY) in Figure 5.

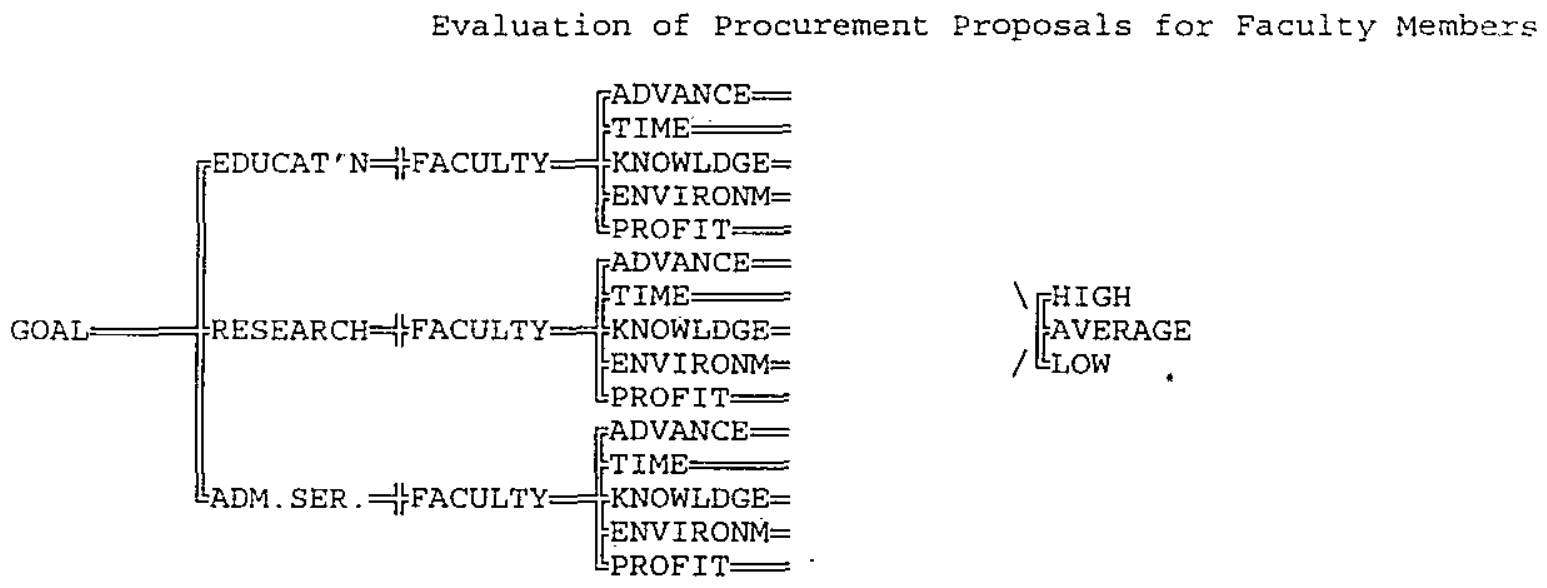

Figure 5. Illustrative Model with one Actor in Evaluating Procurement Proposals

In Table 2, we present the ratings data for four procurement proposals according to faculty members' evaluation.

Table 2. Ranking Data of Illustrative Example

\begin{tabular}{||l|l|l|l|l|l|l||}
\hline Objective & Proposals & ADVANCE & TIME & KNOWLDG & ENVIRONM & PROFIT \\
\hline \multirow{2}{*}{ Educat'n } & PC.Laboratories & AVERAGE & HIGH & HIGH & HIGH & LOW \\
& Telephone net. & AVERAGE & AVERAGE & LOW & HIGH & LOW \\
& Furniture clsrm & AVERAGE & LOW & LOW & HIGH & LOW \\
& Exp. device & AVERAGE & AVERAGE & AVERAGE & AVERAGE & AVERAGE \\
\hline \multirow{3}{*}{ Research } & PC.Laboratories & AVERAGE & AVERAGE & HIGH & LOW & LOW \\
& Telephone net. & AVERAGE & AVERAGE & LOW & HIGH & LOW \\
& Furniture clsrm & LOW & LOW & LOW & LOW & LOW \\
& Exp. device & HIGH & HIGH & HIGH & HIGH & AVERAGE \\
\hline \multirow{2}{*}{ Adm.Ser. } & PC.Laboratories & LOW & LOW & LOW & LOW & LOW \\
& Telephone net. & HIGH & HIGH & HIGH & HIGH & LOW \\
& Furniture clsrm & LOW & LOW & LOW & HIGH & LOW \\
& Exp. device & LOW & LOW & LOW & LOW & HIGH \\
\hline
\end{tabular}

In Table 3, we present the results of evaluation of four procurement proposals. As it is expected, benefits with respect to each objective differs from each other. For example, benefit provided by the expenditures to PC laboratories with respect to education is .330 , and that with respect to administrative services is .056 . This in fact means that $56.6 \%$ of benefits of PC laboratories will serve for education, while $9.7 \%$ will serve for administrative services according to the faculty members' evaluation. 
On the other hand, the results in Table 3 show that faculty members give highest priority to $\mathrm{PC}$ laboratories with respect to education, to the experimentation device with respect to their research activities, and to telephone network with respect to administrative services. However, their first priority is the experimentation device, in global sense.

Table 3. Benefits Obtained by AHP

\begin{tabular}{||l|c|c|c|c|}
\hline PROPOSALS & Education & Research & Adm Services. & TOTAL \\
\hline PC.Laboratories & .330 & .198 & .056 & .583 \\
Telephone net. & .173 & .153 & .169 & .496 \\
Furniture clsrm & .160 & .076 & .078 & .313 \\
Exp. device & .219 & .351 & .056 & .626 \\
\hline
\end{tabular}

\section{RESOURCE ALLOCATION}

After obtaining the benefits of the proposals, we make resource allocation in two stages. In the first stage, we select the proposals which are going to be supported. In the second stage, we allocate at least minimum amount of necessary resource to each selected proposal. In what follows we present the mathematical models and solution algorithms.

\subsection{Selection: Model and Solution}

\section{Notation:}

$\mathrm{N}$ : number of proposals in the beginning

$B$ : budget (available amount of money)

$b_{j}$ : benefit of Proposal $j$.

$l_{j}, u_{j}$ : lower and upper bounds of necessary resource for Proposal $j$.

$\mathrm{x}_{\mathrm{j}}$ : amount of resource allocated to Proposal $\mathrm{j}$ (Decision variable).

The principle constraints of a model for resource allocation would be

1) Budget constraint:

$$
x_{1}+x_{2}+\ldots+x_{N}=B
$$

2) Upper and lower limits of necessary resource for each proposal:

$$
\mathrm{l}_{\mathrm{j}}<\mathrm{x}_{\mathrm{j}}<\mathrm{u}_{\mathrm{j}} \text { for } \mathrm{j}=1,2, \ldots, \mathrm{N}
$$

Since this is a selection model $x_{j}$ should either satisfy (2), or be equal to zero which means that Proposal $\mathrm{j}$ is eliminated (not selected).

Different from the available benefit/cost analysis models, we want to make resource allocation in a way that the ratio of allocated resource to the demanded amount would be 
proportional to the benefit of that proposal; i.e.

$$
\mathrm{x}_{\mathrm{j}} / \mathrm{u}_{\mathrm{j}}=\mathrm{c}_{\mathrm{o}} \mathrm{b}_{\mathrm{j}} \quad \text { for all } \mathrm{j}=1,2, \ldots, \mathrm{N}
$$

where $c_{o}$ is constant, and the ratio $x_{j} / u_{j}$ is called "rate of support". We may state this restriction by the rule "ratio of rates of supports should be equal to the ratio of benefits", which is expressed by

$$
\left(\mathrm{x}_{\mathrm{j}} / \mathrm{u}_{\mathrm{j}}\right) /\left(\mathrm{x}_{\mathrm{i}} / \mathrm{u}_{\mathrm{i}}\right)=\mathrm{b}_{\mathrm{j}} / \mathrm{b}_{\mathrm{i}}
$$

This restriction

$$
\mathrm{c}_{\mathrm{o}}=\mathrm{x}_{1} /\left(\mathrm{b}_{1} \mathrm{u}_{1}\right)=\mathrm{x}_{2} /\left(\mathrm{b}_{2} \mathrm{u}_{2}\right)=\ldots=\mathrm{x}_{\mathrm{N}} /\left(\mathrm{b}_{\mathrm{N}} \mathrm{u}_{\mathrm{N}}\right)
$$

yields a system of $\mathrm{N}-1$ equations in $\mathrm{N}$ variables as the third set of constraints,

$$
x_{j}=\left[\left(b_{j} u_{j}\right) /\left(b_{1} u_{i}\right)\right] x_{1} \quad \text { for all } j=2, \ldots, N
$$

When (6) is solved with the budget constraint (1), the solution is obtained by,

$$
x_{j}=\left(b_{j} u_{j}\right) B /\left(b_{1} u_{1}+b_{2} u_{2}+\ldots+b_{N} u_{N}\right) \text { for all } j=1,2, \ldots, N
$$

The solution violates the constraints (2), if summation $\mathrm{l}_{\mathrm{j}}>\mathrm{B}$; becuse at least one of them will be under lower bound. Even when $l_{j}<B$, the solution may be infeasible.

If $x_{j}>l_{j}$, then it means that Proposal $j$ deserves to be supported, considering both benefits and costs at the same time. This condition implies

$$
\left(b_{j} u_{j} / l_{j}\right) B /\left(b_{1} u_{1}+b_{2} u_{2}+\ldots+b_{N} u_{N}\right)>1
$$

and since $B /\left(b_{1} u_{1}+b_{2} u_{2}+\ldots+b_{N} u_{N}\right)$ is constant, Proposal $j$ will be selected or eliminated depending on $\left(b_{j} u_{j} / l_{j}\right)$. Note that, greater the benefit and/or greater the flexibility in cost range, more likely to be selected for Proposal $j$ exactly reflects the reality. So we begin selecting the proposals one by one in decreasing order of $\left(\mathrm{b}_{\mathrm{j}} \mathrm{u}_{\mathrm{j}} / \mathrm{l}_{\mathrm{j}}\right)$ until summation of least necessary costs over the selected proposals is less than the budget.

\subsection{Resource Allocation: Model and Solution}

Suppose that $n$ proposals are selected, where at least $\mathrm{l}_{\mathrm{j}}$ amount of resource is going to be allocated to each of them. Let $y_{j}(j=1,2, \ldots, n)$ denote the amount of resource allocated to Proposal $j$ (decision variable) additional to the lower bound; $i . e ., y_{j}=x_{j}-1_{j}$. Let $B^{\prime}$ denote the amount of available money after allocating the least necessary amounts; i.e., B' $=\mathrm{B}$-summationl

The budget constraint is similar to (1)

$$
y_{1}+y_{2}+\ldots+y_{n}=B^{\prime}
$$


and the bounds are

$$
0<y_{j}<u_{j}-l_{j} \text { for } j=1,2, \ldots, n
$$

Now the rate of support becomes $y_{j} /\left(u_{j}-l_{j}\right)$, and we again want it to be proportional to the benefit by a constant as in (3);

$$
\mathrm{y}_{\mathrm{j}} /\left(\mathrm{u}_{\mathrm{j}}-\mathrm{l}_{\mathrm{j}}\right)=\mathrm{c}_{1} \mathrm{~b}_{\mathrm{j}} \quad \text { for all } \mathrm{j}=1,2, \ldots, \mathrm{n}
$$

which yields a system of $n-1$ equations in $n$ variables,

$$
y_{j}=\left[\left[b_{j}\left(u_{j}-l_{j}\right)\right] /\left[b_{1}\left(u_{1}-l_{1}\right)\right]\right] y_{1} \quad \text { for all } j=2, \ldots, n
$$

The solution of (12) with the budget constraint (9) is

$$
y_{j}=\left[b_{j}\left(u_{j}-l_{j}\right)\right] B^{\prime} /\left[\left(b_{1}\left(u_{1}-l_{1}\right)+b_{2}\left(u_{2}-l_{2}\right)+\ldots+b_{n}\left(u_{n}-l_{n}\right)\right] \quad \text { for all } j=1,2, \ldots, n\right.
$$

If all $y_{j}<\left(u_{j}-l_{j}\right)$, then the solution is feasible. Otherwise we apply the following solution algorithm:

Step 1. Select $\mathrm{k}$ with highest rate of support and set $\mathrm{y}_{\mathrm{k}}=\mathrm{u}_{\mathrm{k}}-\mathrm{l}_{\mathrm{k}}$.

Step 2. Solve the problem from the beginning by deleting the variable $\mathrm{y}_{\mathrm{k}}$, and the constraints related with $\mathrm{y}_{\mathrm{k}}$ in (10) and (12), and by updating $\mathrm{B}^{\prime}$ by $\mathrm{B}^{\prime}-\left(\mathrm{u}_{\mathrm{k}}-\mathrm{I}_{\mathrm{k}}\right)$.

Step 3. Repeat the above process until you obtain all $\mathrm{y}_{\mathrm{j}}<\left(\mathrm{u}_{\mathrm{j}}-\mathrm{l}_{\mathrm{j}}\right)$ for all remaining $\mathrm{y}_{\mathrm{j}}$ 's.

Then a feasible solution is obtained.

\section{CONCLUSION}

In this study we present a general framework of the hierarchy in evaluation of procurement proposals. Hierarchy would be modified by adding some details, or some other considerations according to the specific conditions, in real life applications. Selection and allocation algorithms are based on the purpose to obtain a solution which satisfies the diverse groups within the university, rather than an optimization model.

\section{References}

[1] Arbel, A., "A University Budget Problem: A Priority-based Approach", Socio-Economic Planning Sciences 17 (1983) 181-189.

[2] Forman, E. H., Saaty, T. L., Selley, M. N., and Waldron, R., Expert Choice, Desicion Support Software, Inc., Pittsburg, 1984.

[3] Kwak, N. K., and Diminnie, C. B., "A Goal Programming Model for Allocating Operating Budgets of Academic Units", Socio-Economic Planning Sciences 21 (1987) 333-339.

[4] Saaty, T. L., The Analytic Hierarchy Process, McGraw-Hill, 1980. .

[5] Schroeder, R. G., "Resource Planning in University Management by Goal Programming", Operatios Research 22 (1975) 700-710.

[6] Sinuany-Stern, Z., "A Network Optimization Model for Budget Allocation in a MultiCampus University", Journal of Operational Research Society 35 (1984) 749-757. 